\title{
PHBV/MWCNT Films: Hydrophobicity, Thermal and Mechanical Properties as a Function of MWCNT Concentration
}

\author{
Ana Paula Lemes ${ }^{1,2, *}$, Thaís Larissa do Amaral Montanheiro ${ }^{1,3} \mathbb{D}^{\mathbb{D}}$, Ana Paula da Silva ${ }^{1}$ and \\ Nelson Durán 2,4 \\ 1 Federal University of São Paulo, Institute of Science and Technology, Technology Laboratory of Polymers \\ and Biopolymers, São José dos Campos, SP 12.231-280, Brazil; tlamontanheiro@gmail.com (T.L.d.A.M.); \\ anapaula.silva.sjc@hotmail.com (A.P.d.S.) \\ 2 State University of Campinas, Institute of Chemistry, Biological Chemistry Laboratory, \\ Campinas, SP 13.083-970, Brazil; duran@iqm.unicamp.br \\ 3 Technological Institute of Aeronautics, Division of Fundamental Sciences, Laboratory of Plasmas and \\ Process, São José dos Campos, SP 12.228-900, Brazil \\ 4 Federal University of ABC, Center of Natural and Human Science, Santo André, SP 09.210-170, Brazil \\ * Correspondence: aplemess@gmail.com; Tel.: +55-12-98133-9889
}

Received: 20 December 2018; Accepted: 21 January 2019; Published: 23 January 2019

\begin{abstract}
The introduction of multi-walled carbon nanotubes (MWCNTs) into polymer matrixes has been an important tool to alter and improve some properties in polymer nanocomposites, including biodegradable polymers such as poly(3-hydroxybutyrate-co-3-hydroxyvalerate) (PHBV). In this work, PHBV nanocomposites with 0.05, 0.50, 1.00, 1.50 and $2.00 \mathrm{wt} \%$ of MWCNTs were produced by solvent casting. MWCNT morphology and structure were characterized by Raman spectroscopy, and transmission electron microscopy (TEM). It was observed that MWCNTs have a considerable amount of amorphous carbon (AC) onto their surface and a wide distribution of the tube diameter. MWCNTs act as the nucleating agent in the PHBV matrix, as verified by differential scanning calorimetry (DSC). Thermogravimetric analysis (TGA) showed that thermal stability was not significantly affected. The nanofiller dispersion into the PHBV matrix was not effective for concentrations from $1 \mathrm{wt} \%$ according to the micrographs obtained in scanning electron microscopy (SEM). The contact angle was changed with the introduction of MWCNTs, turning the nanocomposites hydrophobic and improving the mechanical tensile properties of the PHBV matrix.
\end{abstract}

Keywords: PHBV; carbon nanotube; nanocomposite

\section{Introduction}

Given the difficulty of treating solid urban waste-which presents increasing quantities of polymeric materials - the use of biodegradable polymeric materials has been increasing in recent years. These polymers have a shorter life cycle when compared to the life cycle of conventional polymers, which come from fossil sources. Living organisms can degrade biodegradable polymers and, when discarded under favorable biodegradation conditions, they remain for a short time in the environment, for weeks or even months [1,2].

With this in mind, biodegradable polymers, such as poly(3-hydroxybutyrate-co-3-hydroxyvalerate) (PHBV), have been studied and tested for industrial applications, aiming at the replacement of plastics from fossil sources [3]. PHBV is a straight-chain semicrystalline copolymer belonging to the polyhydroxyalkanoate (PHA) family. These biopolymers are synthesized by some microorganisms as an energy reserve [4]. Due to biodegradability and biocompatibility, PHBV has a high potential 
of application in the production of packaging, personal hygiene products, in agriculture and in medical areas [2,5-13]. However, application of PHBV is limited due to its low thermal and mechanical resistance. Thus, one of the alternatives to improve such properties is the production of nanocomposites.

The production of PHBV nanocomposites with different nanoparticles, such as cellulose nanocrystals [14,15], silver nanoparticles [16,17], graphite nanosheets [18,19], titanium dioxide nanoparticles [20], carbon nanotubes (CNT) [6,21-25] and other nanomaterials, has been studied as an alternative that might improve their thermal and mechanical properties, enabling their utility in certain areas.

Among the nanoparticles most used in the development of polymer nanocomposites are CNTs. CNTs are formed by graphene sheets concentrically rolled with nanometer-wide diameters that can have a length of multiple centimeters [26,27]. Pan et al. [28] observed that the addition of 0.25 to $2.0 \mathrm{wt} \%$ of CNT in a polycaprolactone (PCL) matrix significantly improved the tensile and compressive modulus of the PCL-CNT nanocomposites. Other studies showed that CNTs also acted as great mechanical reinforcement agents for the poly(lactic acid) (PLA) matrix, in which small proportions positively influenced tensile strength, modulus and toughness of the PLA-CNT nanocomposites $[29,30]$.

CNTs have been used as a reinforcing agent in the production of nanocomposites with PHBV, aiming mainly to improve mechanical, thermal and electrical properties of the matrix [6,21-24]. Few works have, as a critical objective, studied the addition of several concentrations of CNT into PHBV nanocomposites and the consequences in polymer properties, especially in regards to hydrophilicity [6,31]. Studies about hydrophilicity are necessary once changes in this characteristic of biodegradable polymers has influenced the degradation carried out by microorganisms and, consequently, the time of deterioration and nanocomposite application.

This work aims to evaluate the effect of CNT concentration on the thermal proprieties of the PHBV matrix through differential scanning calorimetry (DSC) and thermogravimetric analysis (TGA), on morphology by scanning electron microscopy (SEM), on hydrophilicity of the films through their contact angle and on mechanical proprieties using uniaxial tensile tests. CNTs were initially characterized by Raman spectroscopy and transmission electron microscopy (TEM). Besides being an essential tool to improve the dispersion of fillers into a matrix, functionalization is an additional step, which would add time and cost to the final material. The goal of this work is to produce nanocomposites of PHBV and multi-walled carbon nanotubes (MWCNTs) that achieve a satisfactory dispersion of MWCNTs without the need of any previous step. To our knowledge, there is no previous study of PHBV/MWCNT to have evaluated the effect of different MWCNTs concentrated into PHBV films that concerned thermal properties, morphology, mechanical properties or, especially, contact angle.

\section{Materials and Methods}

PHBV was supplied by PHB Industrial Ltd. (São Paulo, Brazil), with a $15 \mathrm{~mol} \%$ of hydroxyvalerate units and molecular weight (Mw) of $230.000 \mathrm{~g} \cdot \mathrm{mol}^{-1}$. Multi-walled carbon nanotubes (MWCNTs) were produced by chemical vapor deposition with a minimum purity of $93 \%$ (weight), supplied by CNT CO. Ltd. (Incheon, Korea). The diameter range of the MWCNTs was from 10 to $40 \mathrm{~nm}$, and the length was from 5 to $20 \mu \mathrm{m}$.

PHBV/MWCNT nanocomposites with 0.05, 0.50, 1.00, 1.50 and $2.00 \mathrm{wt} \%$ of MWCNTs were prepared by solvent casting according to our previous works [21,22]. A solution of $8 \mathrm{wt} \%$ of PHBV in chloroform $\left(\mathrm{CHCl}_{3}\right)$ was prepared under heating. This solution was added in a suspension of MWCNTs in chloroform, previously sonicated in an ultrasonic processor (VCX 750 Sonics, $750 \mathrm{~W}$; $20 \mathrm{kHz}$ ) for $2 \mathrm{~min}$. After, the mixture of PHBV and MWCNTs in chloroform was sonicated for $1 \mathrm{~min}$, then poured in Petri plates. The mixtures were allowed to stand overnight, and the films were formed after the evaporation of the chloroform. 
A Raman spectrum of MWCNTs was obtained using a Raman Renishaw Imaging Microprobe System 3000 spectrometer, coupled with an optical microscope, using spatial resolution of $1.5 \mu \mathrm{m}$ and a He-Ne laser $(632.5 \mathrm{~nm})$.

Transmission electron microscopy images of MWCNTs were obtained using 300-mesh carbon-coated copper grids. Images were acquired on a Carl Zeiss (CEM-902, Oberkochen, Germany) instrument, operating at $80 \mathrm{kV}$.

Differential scanning calorimeter (DSC) measurements of PHBV/MWCNT nanocomposites with $0.05,0.50,1.00,1.50$ and $2.00 \mathrm{wt} \%$ of MWCNTs were carried out using a DSC Q10 from TA Instruments. Samples were sealed in an aluminum DSC pan and heated from room temperature to $200{ }^{\circ} \mathrm{C}$ at $10^{\circ} \mathrm{C} \cdot \mathrm{min}^{-1}$. They were kept at $200^{\circ} \mathrm{C}$ for $2 \mathrm{~min}$ to eliminate the previous heat history and subsequently cooled to $-30^{\circ} \mathrm{C}$ at $10^{\circ} \mathrm{C} \cdot \mathrm{min}^{-1}$, and held at this temperature for $2 \mathrm{~min}$. After this, they were heated to $200{ }^{\circ} \mathrm{C}$ at $10{ }^{\circ} \mathrm{C} \cdot \mathrm{min}^{-1}$ under nitrogen atmosphere with a flow rate of $50 \mathrm{~mL} \cdot \mathrm{min}^{-1}$.

The $\%$ of crystallinity was calculated according to the relation $\mathrm{Xc}(\%)=\Delta \mathrm{H}_{\mathrm{m}}{ }^{1} / \mathrm{W}_{\mathrm{PHBV}^{*}} \Delta \mathrm{H}_{\mathrm{m}}{ }^{0}$, where $\Delta \mathrm{H}_{\mathrm{m}}{ }^{1}$ is the total melting enthalpy on second heating, $\mathrm{W}_{\mathrm{PHBV}}$ is the weight fraction of PHBV in the nanocomposite and $\Delta_{\mathrm{Hm}}{ }^{0}$ is the theoretical melting-heat value of $100 \%$ crystalline PHBV, which was taken as $109 \mathrm{~J} \cdot \mathrm{g}^{-1}$ [23].

Thermal stability of PHBV/MWCNT nanocomposites was investigated by thermogravimetric analysis (TGA) in an SDT Q600 from TA Instrument. The samples were heated at $10^{\circ} \mathrm{C} \cdot \mathrm{min}^{-1}$ from room temperature to $600{ }^{\circ} \mathrm{C}$ under nitrogen atmosphere with a flow rate of $100 \mathrm{~mL} \cdot \mathrm{min}^{-1}$.

Fracture surface morphology of the nanocomposites was observed by scanning electron microscopy (SEM) using a Jeol JSM-T300 (Peabody, MA, USA) microscope operating at $20 \mathrm{keV}$. The samples were prepared by cryogenic fracture in liquid nitrogen. The samples were covered with a Pd-Au alloy in a Sputter Coater SCD 050 Baltec (Scotia, NY, USA).

Static contact-angle measurements of the nanocomposites were examined in air at room temperature using a Drop Shape Analyzer DSA 100 from Krüss (Hamburg, Germany). Contact-angle values were automatically calculated using DSA software. Measurements were made by dropping $10 \mu \mathrm{L}$ of water on $1 \mathrm{~cm} \times 1 \mathrm{~cm}$ PHBV / MWCNT film samples fixed on glass blades. Contact-angle values were obtained using the average of five measurements.

Uniaxial tensile tests of PHBV/MWCNT nanocomposites were measured according to ASTM D882-02, using a DL 2000 Universal Test Machine from EMIC (São José dos Pinhais, PR, Brazil), with a load cell of $500 \mathrm{~N}$ and a $2.5 \mathrm{~mm} \mathrm{~min}^{-1}$ speed of testing. Samples were kept at $23{ }^{\circ} \mathrm{C}$ and $50 \%$ humidity for $48 \mathrm{~h}$ to reach the equilibrium state before their mechanical tests. They were cut into strips with average dimensions of $75 \mathrm{~mm} \times 5 \mathrm{~mm} \times 0.08 \mathrm{~mm}$ (length $\times$ width $\times$ thickness).

\section{Results}

\subsection{Characterization of MWCNTs}

Raman spectroscopy is a widely used technique for the characterization of CNTs that provides information on the degree of crystal lattice disorder. The Raman spectrum obtained for MWCNTs is shown in Figure 1. The bands of most interest in the spectrum were D and G, at $1334 \mathrm{~cm}^{-1}$ and $1587 \mathrm{~cm}^{-1}$, respectively. While the $G$ band can be attributed to $E_{2 g}$ symmetry vibrations in the graphite plane, the $\mathrm{D}$ band is attributed to breakage on the $\mathrm{sp}^{2}$ vibration of 6-membered rings. Thus, the $\mathrm{D}$ band is attributed to disordered carbon present in the structure of MWCNTs, and the G band is attributed to the ordered carbon, analogous to the bands observed for the graphite band [32-34]. The presence of a shoulder in the $G$ band, around $1615 \mathrm{~cm}^{-1}$ (labeled as the $\mathrm{D}^{\prime}$ band), was due to defects in the graphite structure and disordered carbon similar to the D band [35], which is also verified in the spectrum of Figure 1. 


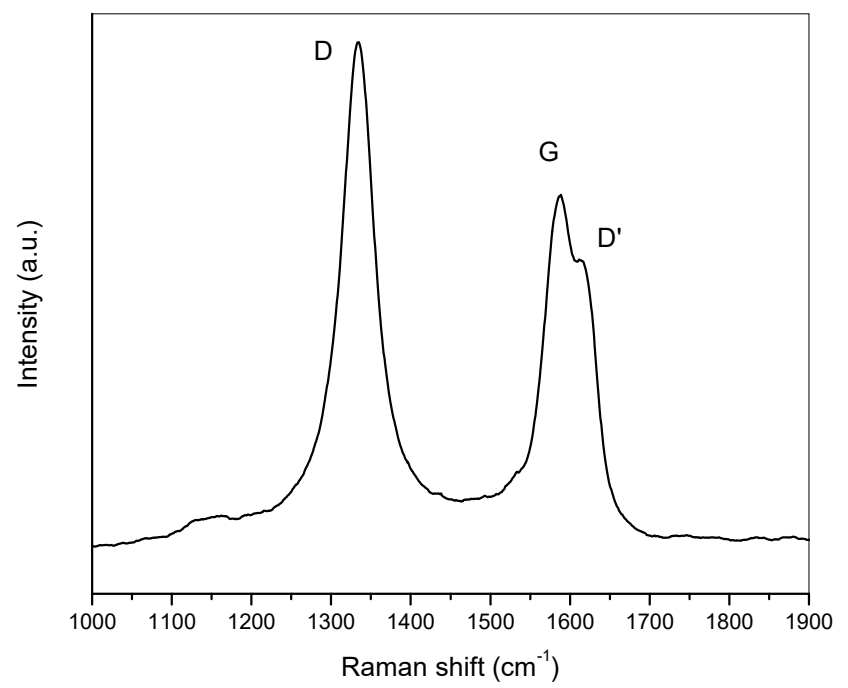

Figure 1. Raman spectrum of multi-walled carbon nanotubes (MWCNTs).

The ratio between the intensities of the $\mathrm{G}$ and $\mathrm{D}\left(\mathrm{I}_{\mathrm{G}}-\mathrm{I}_{\mathrm{D}}\right)$ bands was used to evaluate the amount of disordered carbon atoms in the MWCNT surface [21,22]. Herein, an $\mathrm{I}_{\mathrm{G}}-\mathrm{I}_{\mathrm{D}}$ value of 0.54 was obtained.

Transmission microscopy analysis was performed with the purpose of characterizing the morphology of MWCNTs. Some characteristics of MWCNTs, including diameter and length, as well as impurities found in them, are directly related to their production method. Thus, as the MWCNTs used in this work were obtained by thermochemical vapor deposition (TCVD), TEM micrographs revealed the presence of metallic catalyst particles (MP), amorphous carbon (AC) and a wide distribution of tube diameters, which directly related to the diameter of the metal particle (Figure 2). The black region in Figure 2a is an agglomerate of MWCNTs, amorphous carbon and, probably, metallic particles. However, the overlapping of the materials makes it impossible to identify the contour of each component within this darkened region.
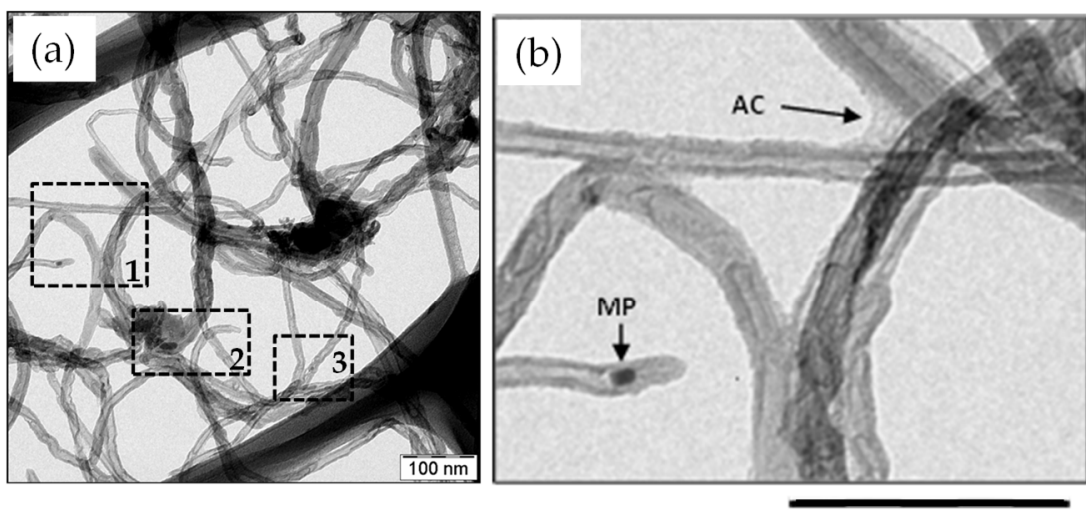

$100 \mathrm{~nm}$

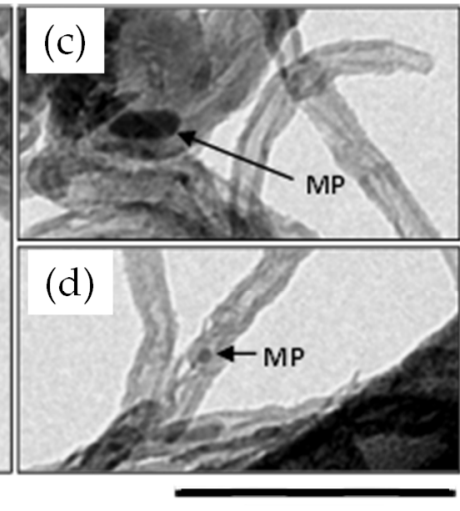

$100 \mathrm{~nm}$

Figure 2. (a) TEM image of MWCNTs; (b) magnification region 1; (c) magnification region 2; (d) magnification region 3. MP: metallic catalyst particles; AC: amorphous carbon.

The variation in the dimensions of metal particles and tube diameters, as well as the deposition of amorphous carbon, is more clearly verified by performing a zoom in the micrographs. Magnified regions are shown in Figure $2 b-d$. It is possible to observe three metal particles of different sizes contained within some filaments here, in addition to a significant deposition of amorphous carbon between the nanotubes (Figure 2b). Amorphous carbon comes from the deposition of hydrocarbon on the outer walls of the filaments. It can be seen that MWCNTs have closed and conical caps (Figure 2b,c). The presence of conical caps is typical of carbon nanotubes, and it is believed that their formation occurs 
due to the presence of pentagonal rings inserted between the hexagonal rings that are a constituent part of graphite sheets [36].

\subsection{Characterization of Nanocomposite Films}

DSC analyses were performed to determine the melting and crystallization behaviors of PHBV and its nanocomposites. Figure 3 shows the DSC curves for neat PHBV and its nanocomposites with different concentrations of MWCNTs.
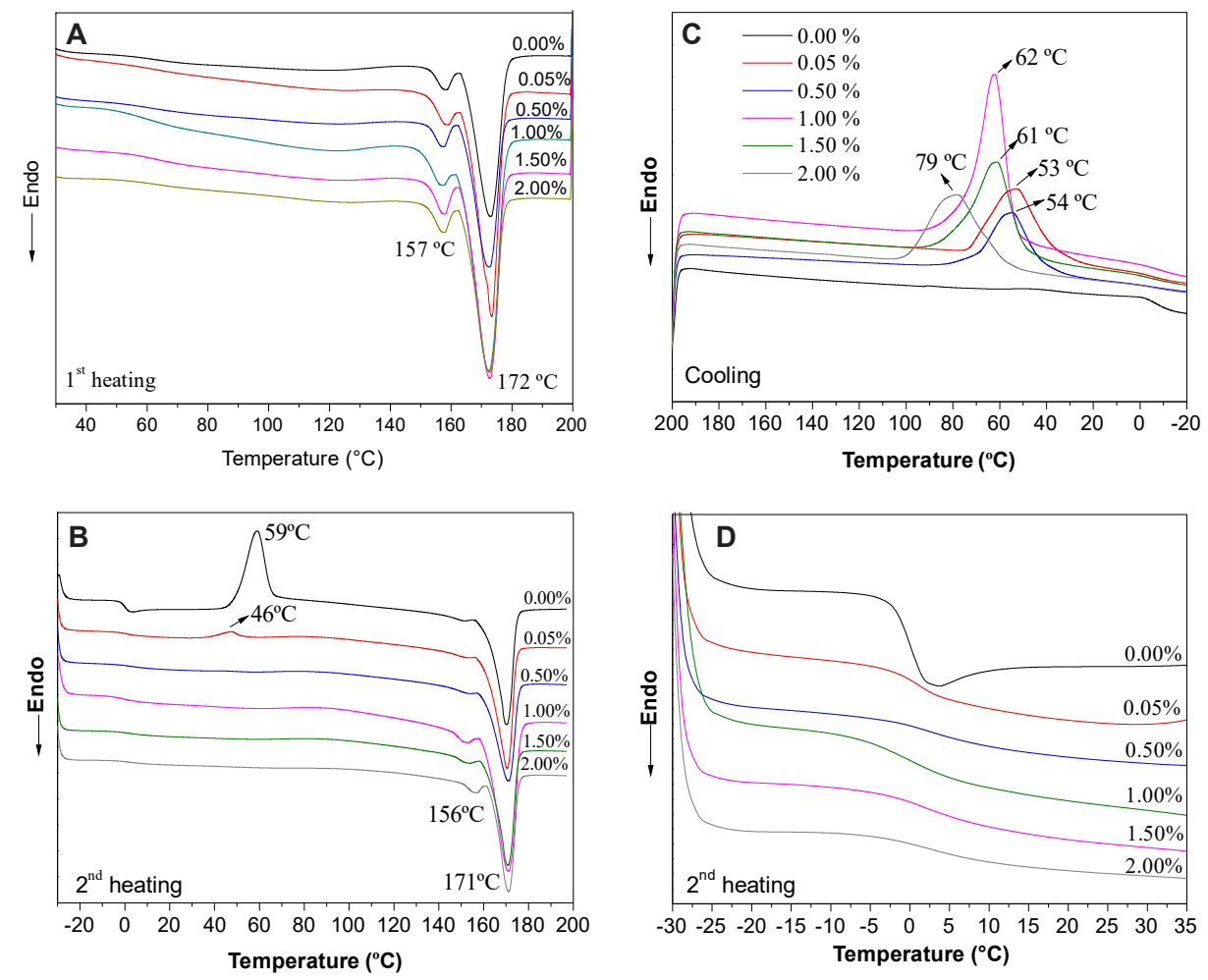

Figure 3. Differential scanning calorimeter (DSC) curves for neat poly(3-hydroxybutyrate-co-3hydroxyvalerate) (PHBV) and its nanocomposites: (a) 1st heating; (b) cooling; (c) 2nd heating; and (d) glass transition region from 2 nd heating.

Bimodal endothermic peaks at $157^{\circ} \mathrm{C}$ and $172{ }^{\circ} \mathrm{C}$ were observed during the first and second heating scans of all the samples (Figure $3 \mathrm{a}, \mathrm{b}$ ). However, in the second heating, the first endothermic peak was attenuated. Figure $3 c$ shows the effects of adding MWCNTs into PHBV on the crystallization behavior of the polymer during the cooling scan. For neat PHBV there was no crystallization peak during the cooling scan, and for all the nanocomposites a crystallization peak could be observed. Crystallization of neat PHBV happened only during the second heating scan, at $59^{\circ} \mathrm{C}$, as shown in Figure 3b.

The glass transition temperature (Tg) can be observed in Figure $3 \mathrm{~d}$. The Tg value for neat PHBV was $0 \pm 1{ }^{\circ} \mathrm{C}$ and for the nanocomposites was $1.75 \pm 1^{\circ} \mathrm{C}$. The baseline variation, related to the heat capacity change $(\triangle \mathrm{Cp})$, was reduced with the increase of MWCNT concentration.

Table 1 shows the values of crystallization temperature (Tc) obtained in the cooling samples, melting enthalpy $(\triangle \mathrm{Hm})$ and degree of crystallinity $\left(\mathrm{X}_{\mathrm{c}}\right)$ for neat PHBV and the nanocomposites with MWCNTs obtained in the second heating. It can be observed that the crystallization of the PHBV matrix occurred in higher temperatures as a function of MWCNT concentration. The increase of MWCNT concentration in nanocomposites also led to an increase in $\mathrm{Xc}_{\mathrm{c}}$. Thus, the crystalline fraction was $56.1 \%$ for neat PHBV, while the nanocomposite with $2.00 \mathrm{wt} \%$ of MWCNTs showed a crystalline fraction of $69.6 \%$. 
Table 1. Values of melting enthalpy $(\Delta \mathrm{Hm})$ and degree of crystallinity $\left(\mathrm{X}_{\mathrm{c}}\right)$ in $\mathrm{PHBV} / \mathrm{MWCNT}$ nanocomposites.

\begin{tabular}{cccc}
\hline MWCNT wt \% & Tc $\left({ }^{\circ} \mathbf{C}\right)$ & $\Delta \mathbf{H m}\left(\mathbf{J} \cdot \mathbf{g}^{-\mathbf{1}}\right)$ & Xc (\%) \\
\hline 0.00 & - & 61.2 & 56.1 \\
0.05 & 53 & 69.6 & 63.9 \\
0.50 & 54 & 59.3 & 54.7 \\
1.00 & 62 & 59.0 & 54.7 \\
1.50 & 61 & 69.5 & 64.7 \\
2.00 & 79 & 74.4 & 69.6 \\
\hline
\end{tabular}

Thermal degradation behaviors of neat PHBV and PHBV/MWCNT nanocomposites were examined using thermogravimetry under a $\mathrm{N}_{2}$ flow. TGA curves are shown in Figure 4.

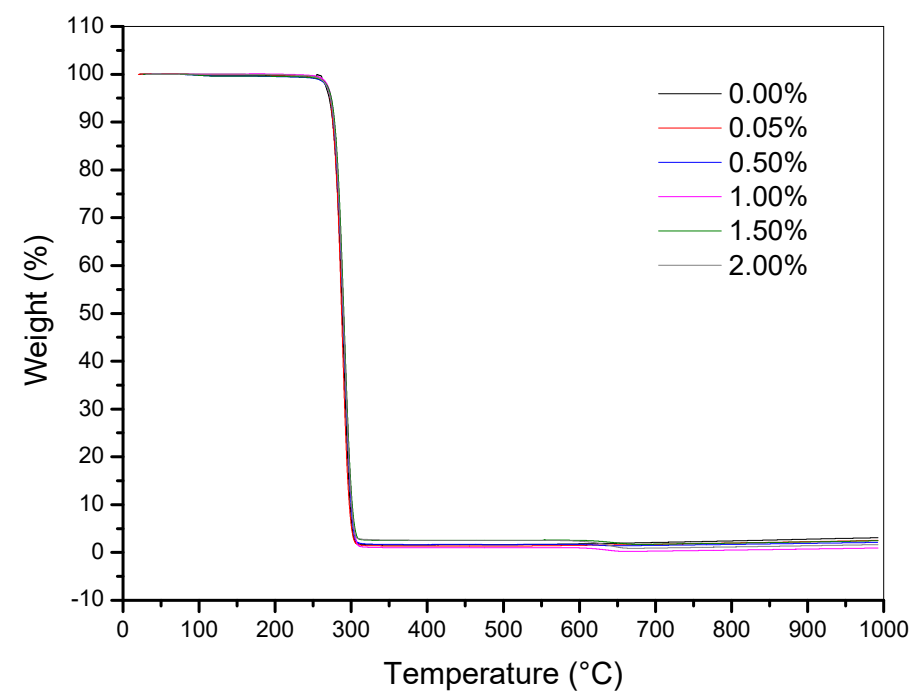

Figure 4. Thermogravimetric curves of neat PHBV and nanocomposites.

Thermal degradation of each sample was evaluated by observing the temperature at 1, 5 and 10\% weight loss (T1, T5 and T10, respectively) and the temperature at the maximum weight-loss rate (Tmax). Values of Tmax were obtained with the first derivative of each curve, shown in Table 2.

Table 2. Temperatures at 1, 5 and 10\% weight loss (T1, T5 and T10, respectively) and temperature at the maximum weight-loss rate (Tmax) as a function of MWCNT content in the nanocomposites of $\mathrm{PHBV} / \mathrm{MWCNT}$.

\begin{tabular}{ccccc}
\hline MWCNT wt \% & T1 $\left({ }^{\circ} \mathbf{C}\right)$ & T5 $\left({ }^{\circ} \mathbf{C}\right)$ & T10 $\left({ }^{\circ} \mathbf{C}\right)$ & Tmax $\left({ }^{\circ} \mathbf{C}\right)$ \\
\hline 0.00 & 260 & 266 & 269 & 279 \\
0.05 & 261 & 269 & 276 & 283 \\
0.50 & 260 & 269 & 273 & 285 \\
1.00 & 261 & 270 & 274 & 285 \\
1.50 & 261 & 270 & 274 & 285 \\
2.00 & 259 & 268 & 272 & 283 \\
\hline
\end{tabular}

Values of T1 and T5 showed that at the beginning of thermal degradation there was no significant difference between the thermal degradation of nanocomposites and that from neat PHBV.

However, after $10 \%$ of weight loss, higher values of T10 could be observed for nanocomposites. The increase of thermal stability was about $7^{\circ} \mathrm{C}$ for nanocomposites containing $0.05 \mathrm{wt} \%$ of MWCNTs and about $4{ }^{\circ} \mathrm{C}$ for other nanocomposites, which showed very similar T10 $\left(\sim 273{ }^{\circ} \mathrm{C}\right)$. Values of 
Tmax for all nanocomposites were about the same $\left(\sim 284^{\circ} \mathrm{C}\right)$, which corresponded to an increase of approximately $5^{\circ} \mathrm{C}$ compared to neat PHBV $\left(\sim 279^{\circ} \mathrm{C}\right)$.

Dispersion of MWCNTs and the interface between them and the polymeric matrix can be evaluated in the fracture-surface micrographs of the nanocomposites shown in Figure 5, where most representative samples are exhibited.
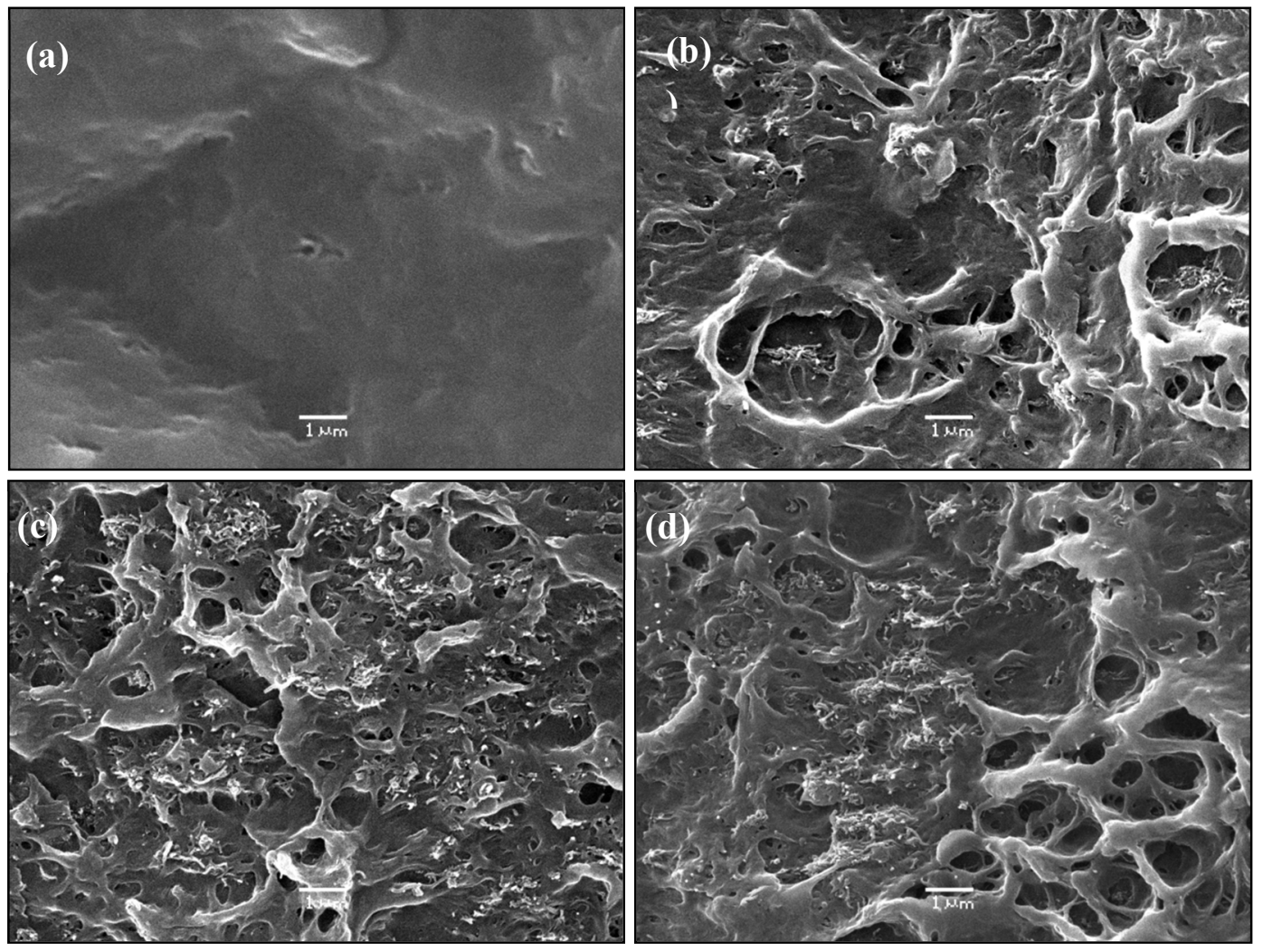

Figure 5. Fracture-surface SEM images of PHBV/MWCNT nanocomposites: (a) 0.00 wt \%; (b) 0.50 wt $\%$; (c) $1.00 \mathrm{wt} \%$; (d) $2.00 \mathrm{wt} \%$ of MWCNTs.

For neat PHBV the fracture resulted in a smooth surface, while nanocomposites showed a very rough surface.

Wettability of PHBV/MWCNT film surfaces was evaluated by static contact-angle measurements of water droplets deposited on the smooth (the surface in contact with the glass surface of the Petri dish) and rough (the surface in contact with atmospheric air) surfaces of the films produced. Results represented an average of five measurements.

Images of the contact angle of rough surfaces of PHBV/MWCNT nanocomposites with 0.05 and $1.00 \mathrm{wt} \%$ are shown in Figure 6a. Smooth and rough surfaces of neat PHBV films showed an average contact angle of $56^{\circ}$ and $55^{\circ}$, respectively (Figure $6 \mathrm{~b}$ ).

On both smooth and rough surfaces of the nanocomposites, an increase of the contact angle as a function of MWCNT concentration in the sample was observed, indicating a decrease in the hydrophilic character of the surface. As the concentration of MWCNTs in the nanocomposites increased, the amount of MWCNTs exposed on the film surface (both smooth and rough) also grew, as shown in the micrographs.

Uniaxial tensile tests were peformed with neat PHBV and nanocomposites. Mean values and standard deviation for tensile strength, elongation at break and tensile modulus obtained are shown in Table 3. 

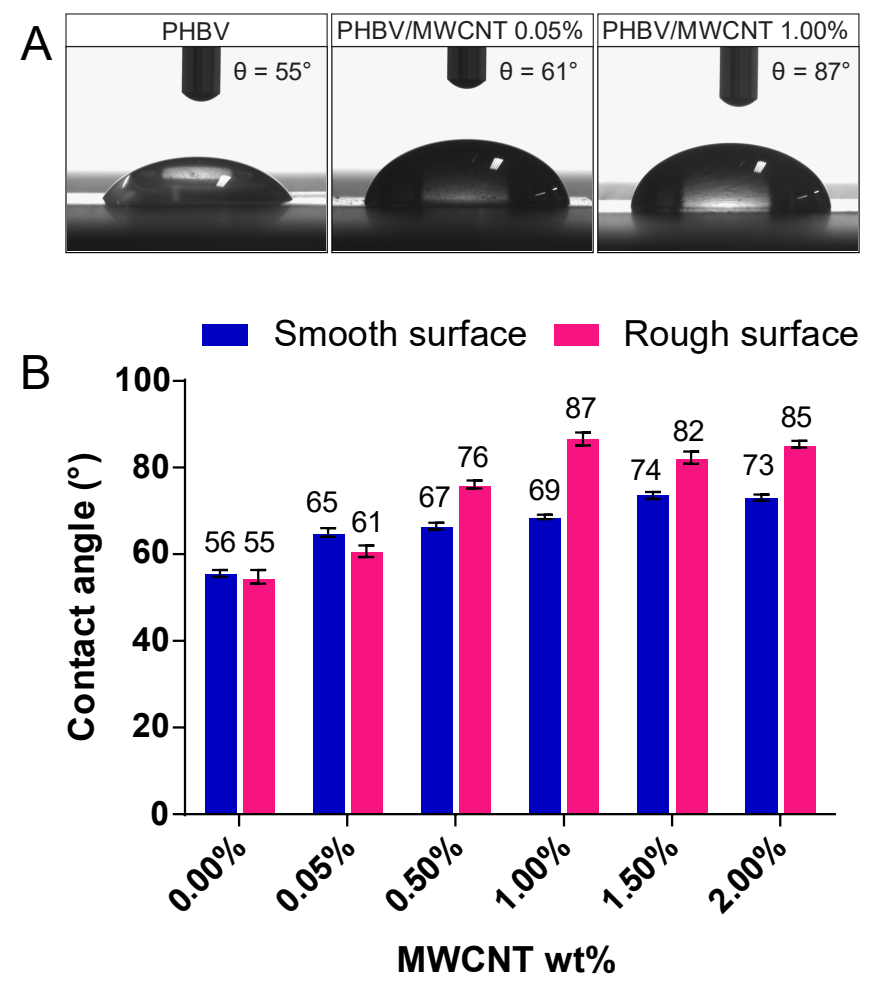

Figure 6. (A) Contact angle in the rough surface of PHBV after the addition of 0.05 and $1.00 \%(w / w)$ of MWCNTs. (B) Contact-angle values of smooth and rough surfaces of PHBV/MWCNT nanocomposites.

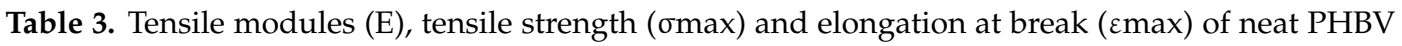
and nanocomposites.

\begin{tabular}{cccc}
\hline MWCNT (\%) & E $\mathbf{( M P a )}$ & $\boldsymbol{\sigma m a x}(\mathbf{M P a})$ & $\varepsilon \max (\%)$ \\
\hline 0.00 & $847 \pm 94$ & $15.59 \pm 0.93$ & $4.64 \pm 0.50$ \\
0.05 & $1001 \pm 36$ & $18.13 \pm 1.31$ & $2.70 \pm 0.22$ \\
0.50 & $998 \pm 87$ & $21.04 \pm 0.80$ & $2.45 \pm 0.14$ \\
1.00 & $875 \pm 87$ & $19.67 \pm 1.39$ & $2.24 \pm 0.24$ \\
1.50 & $1250 \pm 62$ & $23.23 \pm 0.60$ & $2.92 \pm 0.12$ \\
2.00 & $1165 \pm 116$ & $19.21 \pm 2.50$ & $1.79 \pm 0.21$ \\
$p^{*}$ & 0.010 & $8.6 \times 10-7$ & 0.006 \\
\hline \multicolumn{4}{c}{$p^{*}=$ from ANOVA test. }
\end{tabular}

The tensile modulus, tensile strength and elongation at break data presented in Table 3 were statistically analyzed using the parametric ANOVA test and a t-test, with significance established at $5 \%(p<0.05)$.

Analyzing the data in Table 3, an increase in tensile modulus and tensile strength is observed, along with a decrease in elongation at break for all nanocomposite samples compared to neat PHBV. ANOVA applied to the data shows $p<0.05$ in all cases, demonstrating that there was a statistically significant difference between the samples.

In general, an increase was observed in tensile modulus and tensile strength with the increase of MWCNT content in the nanocomposites, despite the observed oscillation of the samples with 0.05 , 0.50 and $1.00 \mathrm{wt} \%$ of MWCNTs. However, a t-test applied to these samples indicated no statistically significant difference between each of these three nanocomposites.

\section{Discussion}

Raman analysis of MWCNTs shows a considerable amount of amorphous carbon and defects in the carbon wall, because of the intensity of $\mathrm{D}$ band, resulting in an $\mathrm{I}_{\mathrm{G}}-\mathrm{I}_{\mathrm{D}}$ ratio of 0.54 . Raman result 
agreed with the TEM images and was very close to the value reported by Liu et al. [32]. In the TEM images, besides the presence of amorphous carbon and defects in the carbon wall, variable diameters and long-length tubes can be observed.

Bimodal endothermic peaks observed during the first and second DSC heating scans of all the samples are attributed to the melting of the crystalline fraction of PHBV. Double melting peaks were similarly seen on PHB and other polymers. The appearance of these peaks is explained by the melting of crystals with distinct lamellar thickness and/or different crystal structures [18,37]. In the second heating, the endothermic peak at $157^{\circ} \mathrm{C}$ was attenuated due, probably, to higher control and a lower ratio of samples cooling, which resulted in a more homogenous spherulite size. Montanheiro et al. [21] studied PHBV/MWCNT nanocomposites with $0.5 \mathrm{wt} \%$ of MWCNTs, and also observed the presence of double melting peaks.

In the DSC scan, the absence of exothermic peaks for nanocomposites during the second heating scan indicates that the crystallization of the PHBV matrix happened entirely during the cooling scan, except for the nanocomposite containing $0.05 \mathrm{wt} \%$ of MWCNTs. For that nanocomposite, a small fraction of PHBV crystallized during the second heating scan, probably because the fraction of MWCNTs was not enough to promote the complete crystallization of PHBV during the cooling scan.

The glass transition temperature ( $\mathrm{Tg}$ ) was not significantly affected; however, the baseline variation indicates that the amorphous phase of the nanocomposites was reduced.

The absence of a crystallization process in the cooling of neat PHBV and the increase of Tc in the function of MWCNTs in nanocomposites indicate that MWCNTs act as nucleating agent. This is also confirmed by the values in Table 1 , which show, generally, that $\Delta \mathrm{Hm}$ increases with MWCNT concentration.

In the TGA results, the addition of MWCNTs in the PHBV matrix resulted in a small shift of the nanocomposite curves to higher temperatures compared to neat PHBV $(0.00 \mathrm{wt} \%)$ for all the contents of MWCNTs. Therefore, the data of Table 2 show a small increase in thermal stability of the PHBV matrix with the introduction of MWCNTs after $10 \%$ weight loss. However, the increase of MWCNT concentration did not result in a proportional increase in thermal stability, maybe due to the difficulty of MWCNT dispersion with the increase of their concentration.

Previous studies [21] showed improvement in the initial thermal degradation of PHBV nanocomposites produced with $0.5 \mathrm{wt} \%$ of MWCNTs, which was attributed to a hindering of the transport of combustion gas with the absorption of free radicals generated during polymer decomposition by the activated carbon surface. An effective barrier to the permeation of combustion gas would only work in the case of well-dispersed MWCNTs [24,38,39].

The fracture surface, observed by SEM, demonstrated that neat PHBV results in a smooth surface featuring a hard and brittle material, while nanocomposites produce a very rough surface, indicating a greater deformation before rupture. Micrographs show the dispersion of MWCNTs inside the nanocomposites. Despite the existence of several individual MWCNTs, increasing the concentration of MWCNTs in the nanocomposites hampers their dispersion in the polymer matrix. Thus, the nanocomposites containing 1.00 and $2.00 \mathrm{wt} \%$ of MWCNTs had large areas of agglomerated tubes, agreeing with the results observed in thermogravimetric analysis, which did not show considerable improvements in thermal degradation temperatures due to, probably, an inefficient dispersion of MWCNTs within the PHBV matrix.

Changes in chemical composition and roughness of PHBV/MWCNT nanocomposite surfaces resulted in wettability changes in the final material due to the high hydrophobicity of the MWCNTs [22].

The wettability of neat PHBV is significant since surfaces with a contact angle less than $90^{\circ}$ are classified as hydrophilic [40]. Neat PHBV is, therefore, a partially hydrophilic substrate once it is a polyester, and hydrogen bonds can be established with water molecules on its surface.

The presence of MWCNTs caused a reduction of nanocomposite surface polarity due to hydrophobicity of the MWCNTs. Comparing smooth surfaces from neat PHBV $\left(\theta=56^{\circ}\right)$ and $\mathrm{PHBV} / \mathrm{MWCNT} 1.50 \mathrm{wt} \%\left(\theta=74^{\circ}\right)$, an increase of $18^{\circ}$ in the contact angle was observed, meaning 
an increase of about $32 \%$. In the case of the rough surface, comparing neat $\operatorname{PHBV}\left(\theta=55^{\circ}\right)$ and $\mathrm{PHBV} / \mathrm{MWCNT} 1.00 \mathrm{wt} \%\left(\theta=87^{\circ}\right)$, the increase was $32^{\circ}$ in the contact angle $(\sim 58 \%)$, as shown in Figure $6 \mathrm{~b}$. The same behavior was observed in our previous study [22].

The most apparent increase in the case of the rough surface is attributed to exposure to a more significant number of MWCNTs and, consequently, higher roughness and chemical heterogeneity compared to the smooth surface. The roughness and chemical heterogeneity of the surface contributed to the increase in the contact angle [40]. The increase in the MWCNT concentration implies an increase in the number of MWCNTs on both the rough and the smooth surface and, consequently, an increase in their hydrophobicity.

The low concentration of MWCNTs in the $0.05 \mathrm{wt} \%$ sample did not influence the roughness of the films, and resulted in similar contact-angle values for smooth and rough surfaces. Although the smooth surface showed greater hydrophobicity than the rough surface, which was not expected, this difference was small compared to the other concentrations. While the difference between the contact angle of the smooth and rough surfaces of the $0.05 \mathrm{wt} \%$ nanocomposite was $3^{\circ}$, for different concentrations this difference varied between $8^{\circ}(1.5 \%)$ and $18^{\circ}(1.0 \%)$. The difference between the values of the smooth and rough surfaces was not proportional to the increase of MWCNT concentration because of the heterogeneity of the samples. However, hydrophobicity increased, despite the low concentration of MWCNTs in the $0.05 \mathrm{wt} \%$ nanocomposite, compared to pure PHBV.

The reduction of hydrophilicity may be attractive in cases where it is necessary to control the degradation rate of the material, since the penetration of water molecules into the nanocomposites would be harmed, and would reduce the cleavage of PHBV side chains [41].

Adding MWCNTs to the PHBV matrix resulted in an increase of the material strength and stiffness, and, consequently, in a decrease of the elongation at break. Thus, the sharpest reduction was verified for the sample with $2.00 \mathrm{wt} \%$ of MWCNTs, which showed a reduction of about $61 \%$ compared to neat PHBV. Addition of MWCNTs into the polymer matrix leading to elongation reduction has been reported in several works $[6,23]$.

The best mechanical properties were observed for the nanocomposite PHBV/MWCNT with $1.50 \mathrm{wt} \%$, showing an increase of $48 \%$ in tensile modulus, $49 \%$ in tensile strength and the smallest elongation at break loss (37\%). Reinforcement effects may be attributed to chain entanglements between MWCNTs and PHBV [6]. Long fillers may have a better efficiency as a reinforcing agent due to the formation of entanglements, which may restrict the deformation of the polymer matrix, but at the same time, it is harder to have a good dispersion within the polymer matrix $[42,43]$.

It was expected that higher values of tensile modulus and tensile strength would be obtained for the sample with $2.00 \mathrm{wt} \%$ of MWCNTs. However, the higher concentration of CNTs hindered their dispersion in the polymer matrix, increasing the heterogeneity of the sample. Thus, we may conclude that the reinforcing effect of MWCNTs in the PHBV matrix was dominant for concentrations less than $1.5 \mathrm{wt} \%$, whereas the effect of MWCNT agglomeration was prevalent at $2.00 \mathrm{wt} \%$ concentration.

\section{Conclusions}

This work reported production and characterization of PHBV/MWCNT nanocomposites with a concentration range from $0.05 \mathrm{wt} \%$ to $2.00 \mathrm{wt} \%$ using solvent casting methodology. Despite MWCNTs having a high tendency of agglomeration, this was sufficient to provide a good dispersion of MWCNTs, resulting in considerable increases of hydrophobicity (58\%) and mechanical resistance (48\%) even with low concentrations of MWCNTs. Some evidence of filler agglomeration was observed above $1.00 \mathrm{wt} \%$, but the values of the measured properties remained high, even if they did not increase proportionally with the concentration of MWCNTs. General thermal behavior was not significantly affected with the introduction of MWCNTs; however, the amorphous phase of the nanocomposites was reduced compared to neat PHBV, and thermal stability was slightly improved after the addition of MWCNTs. The surface contact angle was considerably changed. The introduction of MWCNTs into PHBV reduced the surface polarity of the nanocomposites, resulting in hydrophobic nanocomposites. 
Mechanical tensile modulus and strength were improved with the incorporation of only $1.50 \mathrm{wt} \%$ of MWCNTs.

Author Contributions: Conceptualization, A.P.L. and N.D.; Methodology, A.P.L.; Software, A.P.L.; Validation, A.P.L., N.D. and T.L.d.A.M.; Formal Analysis, A.P.L., T.L.d.A.M. and A.P.d.S.; Investigation, A.P.L.; Resources, A.P.L. and N.D.; Data Curation, A.P.L.; Writing-Original Draft Preparation, T.L.d.A.M. and A.P.d.S.; Writing-Review \& Editing, T.L.d.A.M. and A.P.L.; Visualization, A.P.L., T.L.d.A.M. and A.P.d.S.; Supervision, A.P.L. and N.D.; Project Administration, N.D.; Funding Acquisition, N.D.

Funding: This research was funded by the Brazilian funding institutions CAPES (Coordenação de Aperfeiçoamento de Pessoal de Nível Superior), CNPq (Conselho Nacional de Desenvolvimento Científico e Tecnológico) and FAPESP (Fundação de Amparo à Pesquisa do Estado de São Paulo).

Conflicts of Interest: The authors declare no conflict of interest.

\section{References}

1. Alshehrei, F. Biodegradation of Synthetic and Natural Plastic by Microorganisms. J. Appl. Environ. Microbiol. 2017, 5, 8-19.

2. Raza, Z.A.; Abid, S.; Banat, I.M. Polyhydroxyalkanoates: Characteristics, production, recent developments and applications. Int. Biodeterior. Biodegrad. 2018, 126, 45-56. [CrossRef]

3. Li, Z.; Yang, J.; Loh, X.J. Polyhydroxyalkanoates: Opening doors for a sustainable future. NPG Asia Mater. 2016, 8, 265-285. [CrossRef]

4. Rivera-Briso, A.; Serrano-Aroca, Á. Poly(3-Hydroxybutyrate-co-3-Hydroxyvalerate): Enhancement Strategies for Advanced Applications. Polymers 2018, 10, 732. [CrossRef]

5. Philip, S.; Keshavarz, T.; Roy, I. Polyhydroxyalkanoates: Biodegradable polymers with a range of applications. J. Chem. Technol. Biotechnol. 2007, 82, 233-247. [CrossRef]

6. Yu, H.-Y.; Qin, Z.-Y.; Sun, B.; Yang, X.-G.; Yao, J.-M. Reinforcement of transparent poly(3-hydroxybutyrate-co-3-hydroxyvalerate) by incorporation of functionalized carbon nanotubes as a novel bionanocomposite for food packaging. Compos. Sci. Technol. 2014, 94, 96-104. [CrossRef]

7. Masood, F.; Yasin, T.; Hameed, A. Comparative oxo-biodegradation study of poly-3-hydroxybutyrate-co-3hydroxyvalerate/polypropylene blend in controlled environments. Int. Biodeterior. Biodegrad. 2014, 87, 1-8. [CrossRef]

8. Hazer, D.B.; Kiliçai, E.; Hazer, B. Poly(3-hydroxyalkanoate)s: Diversification and biomedical applications A state of the art review. Mater. Sci. Eng. C 2012, 32, 637-647. [CrossRef]

9. Wu, Q.; Wang, Y.; Chen, G.-Q. Medical Application of Microbial Biopolyesters Polyhydroxyalkanoates. Artif Cells Blood Substit. Biotechnol. 2009, 37, 1-12. [CrossRef]

10. Gorodzha, S.N.; Muslimov, A.R.; Syromotina, D.S.; Timin, A.S.; Tcvetkov, N.Y.; Lepik, K.V.; Petrova, A.V.; Surmeneva, M.A.; Gorin, D.A.; Sukhorukov, G.B.; et al. A comparison study between electrospun polycaprolactone and scaffolds for bone tissue engineering. Colloids Surf. B Biointerfaces 2017, 160, 48-59. [CrossRef]

11. Deepthi, S.; Nivedhitha, S.M.; Vijayan, P.; Nair, S.V.; Jayakumar, R. Engineering poly(hydroxy butyrate-cohydroxy valerate) based vascular scaffolds to mimic native artery. Int. J. Biol. Macromol. 2018, 109, 85-98. [CrossRef] [PubMed]

12. Recco, M.S.; Floriano, A.C.; Tada, D.B.; Lemes, A.P.; Langa, R.; Cristovan, F.H. Poly(3-hydroxybutyrate-covalerate)/Poly(3-thiophene ethyl acetate) blends as electroactive biomaterial substrate to tissue engineering application. RSC Adv. 2016, 6, 25330-25338. [CrossRef]

13. Lemes, A.P.; Soto-Oviedo, M.A.; Innocentini-Mei, L.H.; Durán, N. Processing, chemical structure and morphology of poly(hydroxybutyrate-co-valerate)/lignosulfonate composites. In Proceedings of the ENPROMER-2005, 2nd Mercosur Congress on Chemical Engineering and 4th Mercosur Congress on Process Systems Engineering Enpromer, Rio de Janeiro, Brazil, 14-18 August 2005; pp. 1-6.

14. Ten, E.; Bahr, D.F.; Li, B.; Jiang, L.; Wolcott, M.P. Effects of cellulose nanowhiskers on mechanical, dielectric, and rheological properties of poly(3-hydroxybutyrate-co-3-hydroxyvalerate)/cellulose nanowhisker composites. Ind. Eng. Chem. Res. 2012, 51, 2941-2951. [CrossRef]

15. Du, J.; Zhao, G.; Pan, M.; Zhuang, L.; Li, D.; Zhang, R. Crystallization and mechanical properties of reinforced PHBV composites using melt compounding: Effect of CNCs and CNFs. Carbohydr. Polym. 2017, 168, 255-262. 
16. Castro-Mayorga, J.L.; Martínez-Abad, A.; Fabra, M.J.; Olivera, C.; Reis, M.; Lagarón, J.M. Stabilization of antimicrobial silver nanoparticles by a polyhydroxyalkanoate obtained from mixed bacterial culture. Int. J. Biol. Macromol. 2014, 71, 103-110. [CrossRef]

17. Castro-Mayorga, J.L.; Fabra, M.J.; Lagaron, J.M. Stabilized nanosilver based antimicrobial poly(3-hydroxybutyrate-co-3-hydroxyvalerate) nanocomposites of interest in active food packaging. Innov. Food Sci. Emerg. Technol. 2016, 33, 524-533. [CrossRef]

18. Montagna, L.S.; Montanheiro, T.L.; Machado, J.P.B.; Passador, F.R.; Lemes, A.P.; Rezende, M.C. Effect of Graphite Nanosheets on Properties of Poly(3-hydroxybutyrate-co-3-hydroxyvalerate). Int. J. Polym. Sci. 2017, 2017, 9316761. [CrossRef]

19. Montagna, L.S.; Montanheiro, T.L.; Baldan, M.R.; Oliveira, A.P.S.; de Farias, M.A.; Hocevar, M.A.; Folgueras, L.C.; Passador, F.R.; Lemes, A.P.; Rezende, M.C. Effect of graphite nanosheets on electrical, electromagnetic, mechanical and morphological characteristics of PHBV/GNS nanocomposites. Adv. Mater. Lett. 2018, 9, 499-504. [CrossRef]

20. Braga, N.F.; Vital, D.A.; Guerrini, L.M.; Lemes, A.P.; Formaggio, D.M.D.; Tada, D.B.; Arantes, T.M.; Cristovan, F.H. PHBV-TiO 2 mats prepared by electrospinning technique: Physico-chemical properties and cytocompatibility. Biopolymers 2018, 109, e23120. [CrossRef]

21. Montanheiro, T.L.A.; Cristóvan, F.H.; Machado, J.P.B.; Tada, D.B.; Durán, N.; Lemes, A.P. Effect of MWCNT functionalization on thermal and electrical properties of PHBV/MWCNT nanocomposites. J. Mater. Res. 2014, 30, 55-65. [CrossRef]

22. Montanheiro, T.L.A.; Montagna, L.S.; Machado, J.P.B.; Lemes, A.P. Covalent functionalization of MWCNT with PHBV chains: Evaluation of the functionalization and production of nanocomposites. Polym. Compos. 2017, 40, 288-295. [CrossRef]

23. Vidhate, S.; Innocentini-mei, L.; Souza, N.A.D. Mechanical and Electrical Multifunctional Poly(3hydroxybutyrate-co-3-hydroxyvalerate)-Multiwall Carbon Nanotube Nanocomposites. Polym. Eng. Sci. 2012, 52, 1367-1374. [CrossRef]

24. Yu, H.-Y.; Yao, J.-M.; Qin, Z.-Y.; Liu, L.; Yang, X.-G. Comparison of covalent and noncovalent interactions of carbon nanotubes on the crystallization behavior and thermal properties of poly(3-hydroxybutyrate-co3-hydroxyvalerate). J. Appl. Polym. Sci. 2013, 130, 4299-4307. [CrossRef]

25. Lemes, A.P.; Montanheiro, T.L.A.; Passador, F.R.; Durán, N. Nanocomposites of Polyhydroxyalkanoates Reinforced with Carbon Nanotubes: Chemical and Biological Properties. In Eco-Friendly Polymer Nanocomposites; Springer: New Delhi, India, 2015; pp. 79-108.

26. Qiu, H.; Yang, J. Structure and Properties of Carbon Nanotubes. In Industrial Applications of Carbon Nanotubes; Elsevier Inc.: New York, NY, USA, 2016; pp. 47-69.

27. Jian, M.Q.; Xie, H.H.; Xia, K.L.; Zhang, Y.Y. Challenge and Opportunities of Carbon Nanotubes. In Industrial Applications of Carbon Nanotubes; Elsevier Inc.: New York, NY, USA, 2016; pp. 433-476.

28. Pan, L.; Pei, X.; He, R.; Wan, Q.; Wang, J. Multiwall carbon nanotubes/polycaprolactone composites for bone tissue engineering application. Colloids Surf. B Biointerfaces 2012, 93, 226-234. [CrossRef] [PubMed]

29. Pinto, V.C.; Ramos, T.; Alves, A.S.F.; Xavier, J.; Tavares, P.J.; Moreira, P.M.G.P.; Guedes, R.M. Dispersion and failure analysis of PLA, PLA/GNP and PLA/CNT-COOH biodegradable nanocomposites by SEM and DIC inspection. Eng. Fail Anal. 2017, 71, 63-71. [CrossRef]

30. Park, S.H.; Lee, S.G.; Kim, S.H. Isothermal crystallization behavior and mechanical properties of polylactide/carbon nanotube nanocomposites. Compos. Part A Appl. Sci. Manuf. 2013, 46, 11-18. [CrossRef]

31. Ma, Y.; Zheng, Y.; Wei, G.; Song, W.; Hu, T.; Yang, H.; Xue, R. Processing, Structure, and Properties of Multiwalled Carbon Nanotube/Poly(hydroxybutyrate-co-valerate) Biopolymer Nanocomposites. J. Appl. Polym. Sci. 2012, 125, E620-E629. [CrossRef]

32. Liu, L.; Qin, Y.; Guo, Z.; Zhu, D. Reduction of solubilized multi-walled carbon nanotubes. Carbon N. Y. 2003, 41, 331-335. [CrossRef]

33. Antunes, E.F.; Lobo, A.O.; Corat, E.J.; Trava-Airoldi, V.J.; Martin, A.A.; Veríssimo, C. Comparative study of first- and second-order Raman spectra of MWCNT at visible and infrared laser excitation. Carbon N. Y. 2006, 44, 2202-2211. [CrossRef]

34. Osswald, S.; Havel, M.; Gogotsi, Y. Monitoring oxidation of multiwalled carbon nanotubes by Raman spectroscopy. J. Raman Spectrosc. 2007, 38, 728-736. [CrossRef] 
35. de Menezes, B.R.C.; Ferreira, F.V.; Silva, B.C.; Simonetti, E.A.N.; Bastos, T.M.; Cividanes, L.S.; Thim, G.P. Effects of octadecylamine functionalization of carbon nanotubes on dispersion, polarity, and mechanical properties of CNT/HDPE nanocomposites. J. Mater. Sci. 2018, 53, 14311-14327. [CrossRef]

36. Endo, M.; Takeuchi, K.; Kobori, K.; Takahashi, K.; Kroto, H.W.; Sarkar, A. Pyrolytic carbon nanotubes from vapor-grown carbon fibers. Carbon N. Y. 1995, 33, 873-881. [CrossRef]

37. Gunaratne, L.M.W.K.; Shanks, R.A.; Amarasinghe, G. Thermal history effects on crystallisation and melting of poly(3-hydroxybutyrate). Thermochim. Acta 2004, 423, 127-135. [CrossRef]

38. Lai, M.; Li, J.; Yang, J.; Liu, J.; Tong, X.; Cheng, H. The morphology and thermal properties of multi-walled carbon nanotube and poly(hydroxybutyrate-co-hydroxyvalerate) composite. Polym. Int. 2004, 53, 1479-1484. [CrossRef]

39. Shaffer, M.S.P.; Windle, A.H. Fabrication and Characterization of Carbon Nanotube/Poly(vinyl alcohol) Composites. Adv. Mater. 1999, 11, 937-941. [CrossRef]

40. Cai, Z.; Xu, Y.; Yang, H.; Jia, J.; Liu, Y. Poly(hydroxybutyrate)/cellulose acetate blend nanofiber scaffolds: Preparation, characterization and cytocompatibility. Mater. Sci. Eng. C 2016, 58, 757-767.

41. Yu, H.; Qin, Z.; Zhou, Z. Cellulose nanocrystals as green fillers to improve crystallization and hydrophilic property of poly(3-hydroxybutyrate-co-3-hydroxyvalerate). Prog. Nat. Sci. Mater. Int. 2011, 21, 478-484. [CrossRef]

42. Bauhofer, W.; Kovacs, J.Z. A review and analysis of electrical percolation in carbon nanotube polymer composites. Compos. Sci. Technol. 2009, 69, 1486-1498. [CrossRef]

43. Grady, B.P. Effects of carbon nanotubes on polymer physics. J. Polym. Sci. Part B Polym. Phys. 2012, 50, 591-623. [CrossRef]

(C) 2019 by the authors. Licensee MDPI, Basel, Switzerland. This article is an open access article distributed under the terms and conditions of the Creative Commons Attribution (CC BY) license (http:/ / creativecommons.org/licenses/by/4.0/). 